\title{
Hedonic analysis of the price of UHT-treated milk in Italy
}

\author{
Francesco Bimbo, ${ }^{*} \dagger^{1,2}$ Alessandro Bonanno, $\neq \S^{2}$ Xuan Liu, ${ }^{* 2}$ and Rosaria Viscecchia† \\ *Business Economics Group, School of Social Sciences, Wageningen University, 6706 KN Wageningen, the Netherlands \\ †Dipartimento di Scienze Agrarie, degli Alimenti e dell'Ambiente, Università degli Studi di Foggia, Via Napoli 25, Foggia 71122, Italia \\ ‡Department of Agricultural and Resource Economics, Colorado State University, Fort Collins 80524 \\ $\S$ Department of Agricultural Economics, Sociology and Education, The Pennsylvania State University, State College 16801
}

\begin{abstract}
The Italian market for UHT milk has been growing thanks to both consumers' interest in products with an extended shelf life and to the lower prices of these products compared with refrigerated, pasteurized milk. However, because the lower prices of UHT milk can hinder producers' margins, manufacturers have introduced new versions of UHT milk products such as lactose-free options, vitamin-enriched products, and milk for infants, with the goal of differentiating their products, escaping the price competition, and gaining higher margins. In this paper, we estimated the contribution of different attributes to UHT milk prices in Italy by using a database of Italian UHT milk sales and a hedonic price model. In our analysis, we considered 2 UHT milk market segments: products for infants and those for the general population. We found premiums varied with the milk's attributes as well as between the segments analyzed: n-3 fatty acids, organic, and added calcium were the most valuable product features in the general population segment, whereas in the infant segment fiber, glass packaging, and the targeting of newborns delivered the highest premiums. Finally, we present recommendations for UHT milk manufacturers. Key words: ultra-high-temperature-treated milk, Italy, hedonic price model
\end{abstract}

\section{INTRODUCTION}

Ultra-high-temperature-treated milk is obtained by heating raw milk at temperatures higher than those used for pasteurization for a short time period, which makes it free from pathogens, and then packing it in aseptic materials. Heating time varies depending on the temperature used to produce UHT milk. For a thorough discussion about the several time-temperature schemes

Received June 26, 2015.

Accepted October 10, 2015.

${ }^{1}$ Corresponding author: francesco.bimbo@wur.nl

${ }^{2}$ These authors contributed equally to this paper. employed to produce UHT milk, refer to Walstra et al. (2005). This treatment makes UHT milk commercially sterile and storable at room temperature for 6 to 9 mo (Muehlhoff et al., 2013). Ultra-high-temperature-treated milk first appeared in the North American market in the 1960s and since then has become popular in many other markets, especially in Europe, Asia, and South America (Oupadissakoon and Chambers, 2009).

Recent market estimates valued the global market for UHT milk at $\$ 60.8$ billion in 2012 , with a forecasted annual growth rate of $12.8 \%$ until 2019 to reach an estimated value of $\$ 137.7$ billion (Transparency Market Research, 2013). Today, European countries represent the largest UHT milk markets due to the high consumption of UHT milk among Europeans. It has been estimated that 7 out of 10 Europeans drink UHT milk regularly (Solomon, 2009) and that, among them, Italians show one of the highest per capita annual consumption rates, estimated at $30 \mathrm{~L}$ per individual (Tempesta and Vecchiato, 2013).

In spite of these promising market trends, UHT milk manufacturers face low margins due to the price competition among producers and retailers existing in this market (Troiani, 2014). Thus, in the face of price competition, manufacturers may react to retailers' requests for low prices by attempting to lower their production costs, or they may agree to produce retailer brands, known as private labels, as an alternative to escape the competition for shelf space (Euromonitor, 2014; Troiani, 2014). Alternatively, to increase their margins, UHT milk processors could aim to differentiate their products (Transparency Market Research, 2013). Although some studies have estimated plant costs for different milk processing alternatives (e.g., Chandarana et al., 2006; Tomasula et al., 2014), which may give guidance on how to reduce production costs, to the best of our knowledge, no study has assessed how UHT milk manufacturers can achieve higher prices by producing products with specific attributes as a means to support firms' differentiation strategies. Similar analyses are common in other dairy and nondairy product markets, including yogurt (Carlucci et al., 2013), coffee (Schol- 
lenberg, 2012), wine (Combris et al., 1997; Steiner, 2004; Panzone, 2011), and fruit beverages (Szathvary and Trestini, 2013). In the last few years, UHT manufacturers have differentiated their products by introducing new product attributes, targeting both general consumers and infants and offering products enriched with health-enhancing features, such as lactose-free and organic products, to name a few (Troiani, 2014).

As estimating the value of UHT milk features may provide valuable information for UHT milk companies operating in a market with low profitability, the objective of this research was to assess the premiums associated with UHT milk attributes. To achieve our goal, we used $2 \mathrm{yr}$ of monthly national sales of UHT milk in Italy, focusing on 2 market segments: the general population and infants. By using sales data we attempted to avoid potential drawbacks, such as hypothetical bias, associated with the use of stated preference data (Lusk et al., 2014; Loke et al., 2015). We focused on the Italian market for 2 reasons. First, UHT milk sales account for more than half of all milk sales in Italy, indicating that the products are well accepted by Italian consumers (Tempesta and Vecchiato, 2013). Second, because the Italian UHT milk industry is relatively concentrated (Pieri, 2009), leading companies may have the technical know-how, as well as the financial capability, to invest in product differentiation strategies.

We present a description of the data and model used. We then illustrate the empirical results and conclude by providing recommendations for UHT milk processors and a discussion of potential avenues for future research.

\section{MATERIALS AND METHODS}

\section{Data}

We used monthly national scanner data of UHT milk sales obtained from the Symphony IRI Group, collected from hypermarkets and supermarkets across the Italian territory and spanning a 25-mo period, from November 29, 2010, to December 31, 2012, originally at the European Article Number level. European Article Number barcodes are 13-digit codes used in the coding system at the retail level and are used worldwide for identifying products whose barcodes are read by scanner cash registers at the point of sale where products are sold. These data allowed us to observe the volume and the value of sales for each product, from which we calculated prices $(€ / L)$, and to identify several product attributes, such as fat content, package size, container type, the addition of health-related/enhancing attributes (vitamins, n-3 fatty acids, fiber, and so on), and brand. Information form front-of-package and nutritional labels were retrieved from manufacturers' websites to cross validate the presence of specific attributes in each product. Products produced by small companies, as well as private labels, for which it was impossible to validate product characteristics by retrieving front-of-package and nutritional labels from online websites, were excluded from the analysis. In the final database we retained 331 products, 304 products targeting the general population segment and 27 targeting the segment for infants. The Italian UHT milk market database contains information on products targeted for general consumption and special milk for infants. These types of milk are quite different in terms of average prices, as well as the options available within each of the two markets. In order to determine whether the two markets were to be studied together or separately, we performed a Chow test for structural breaks in the regression parameters (Chow, 1960) using the entire data sample as well as the two subsamples (general population milk and milk for infants). The Chow test statistics are distributed in an F-distribution with a number of degrees of freedom function for the sample sizes and the number of parameters to be estimated. In our case, the value of the $\mathrm{F}$ statistic we obtained $[\mathrm{F}(139,7960)]$ was 2.6378 , which was above the critical value (at the $5 \%$ level of significance) of 1.2075 . Thus, using one equation for each of the two segments would lead to more efficient estimates than using one regression. This result also confirmed the existence of two separate market segments in the UHT milk market. The 331 products retained, defined by unique combinations of attributes, were produced by 15 manufacturers and represented about $85 \%$ of the Italian UHT milk market.

In our analysis we included information on whether a product contained vitamins (Vitamins), fiber (Fiber), minerals other than calcium (Minerals), and n-3 fatty acids (Omega3) and whether the milk contained less than $120 \mathrm{mg} / 100 \mathrm{~mL}$ of calcium (Low_Calcium), equal to $120 \mathrm{mg} / 100 \mathrm{~mL}$ (Regular_Calcium), or more than $120 \mathrm{mg} / 100 \mathrm{~mL}$ (High_Calcium). We also included in our analysis information on whether the product was sold as organic (Organic) or lactose-free (Lactose_Free). Additionally, we gathered information on the fat content of the products and, more specifically, whether the product was sold as skim (Skim), partially skim (Partially_Skim), or whole (Whole) milk. Information about packaging size (Package_Size) and the type of packaging material used - specifically, plastic (Plastic), glass (Glass), or carton (Carton) - was also included in the analysis. Furthermore, we controlled for retail variables to capture variations in retailers' pricing strat- 
egy: number of items per store (Item), percentage of products sold under promotion (Promvol), and average weighted distribution (Dis). The Dis variable measures the number of outlets offering the product, in numeric terms, conditional upon the manufacturer's products being available in a given store. Last, for the infant segment, we included information on whether the product was a specialty milk for newborns (Newborn), weaning milk (Weaning), or growing-up milk (Growingup). A list of the variables included in the model, as well as their average values and standard deviations, are reported in Table 1.

\section{Hedonic Price Model}

In our analysis we applied the standard hedonic price model, as proposed by Rosen (1974). According to hedonic price theory, a product is considered a bundle of attributes. Each consumer chooses the optimal bundle of features that maximizes his/her utility, subject to a budget constraint. Likewise, manufacturers maximize profits by setting a product's price according to the attributes it contains (Rosen, 1974). In a market with products presenting unique bundles of attributes, the marginal bids of buyers and the marginal offers of sellers match at equilibrium. The joint envelope of bids (from demand) and offers (from supply) generate the hedonic price function (Rosen, 1974). The price $P$ of a product $j$ can be described by the following equation:

$$
P_{j}=f\left(\mathbf{Z}_{j}\right),
$$

where $\mathbf{Z}$ is a vector of product attributes belonging to product $j$ and $f($.$) is an unspecified functional form.$ Equation [1] implies that the price consumers pay for product $P$ is a function of the marginal monetary values of $j$ 's attributes Z (Ladd and Suvannunt, 1976), which can be obtained by partially differentiating [1] with respect to each attribute. The marginal, implicit price a consumer pays for an attribute in $\mathbf{Z}$ corresponds to the marginal cost incurred by producers to supply that attribute.

In our case, $\mathbf{Z}$ is divided into 7 vectors: $\mathbf{Z}^{\mathrm{HI}}, \mathbf{Z}^{\mathrm{CC}}$, $\mathbf{Z}^{\mathrm{OC}}, \mathbf{Z}^{\mathrm{P}}, \mathbf{Z}^{\mathrm{I}}, \mathbf{Z}^{\mathrm{R}}$, and $\mathbf{Z}^{\mathrm{B}}$. $\mathbf{Z}^{\mathrm{HI}}$ represents a vector of product characteristics capturing whether a product contains health-enhancing ingredients (HI) or not, and it is indexed by $h(h=1, \ldots, H)$. Our hypothesis is that the presence of health-enhancing ingredients, such as vitamins, fiber, minerals, and n-3 fatty acids, contributes positively to UHT milk prices. The vector $\mathbf{Z}^{\mathrm{CC}}$ contains information on the calcium content, and it is indexed by $c(c=1, \ldots, C)$, whereas the vectors $\mathbf{Z}^{\mathrm{OC}}$ and $\mathbf{Z}^{\mathbf{P}}$ include other product characteristics (OC), such as fat content and whether or not the milk is sold as organic or lactose-free, and package features $(\mathrm{P})$, respectively, and are indexed by $o(o=1, \ldots, O)$ and $p(\mathrm{P}=1, \ldots, P)$, respectively. For the segment of special milk targeting infants, the vector $\mathbf{Z}^{\mathbf{I}}$, indexed by $I(i=1, \ldots, I)$, contains variables capturing information on whether a milk was targeted to newborns (aged below $6 \mathrm{mo}$ ), constituted weaning milk (targeting infants between 6 and 12 mo of age), or was considered "growing-up" milk (targeting toddlers between 1 and 2 yr of age). Last, $\mathbf{Z}^{\mathrm{R}}$ and $\mathbf{Z}^{\mathrm{B}}$ are vectors capturing the role of strategic retail $(\mathrm{R})$ variables and unobservable brand features (B), such as brand image and loyalty, on UHT milk price, and they are indexed by $r(r=1, \ldots, R)$ and $b(b=1, \ldots, B)$, respectively. As pointed out by an anonymous reviewer, the inclusion of retail-level fixed effects may have been more suitable to account for the effect of unobserved retail strategies on UHT milk prices. However, the data at our disposal did not contain details regarding the retail chain selling the products; therefore, retail-specific fixed effects could not be included. We provide a brief discussion of the implication of this omission in the last section of this article.

In our study, we used a single-equation approach (Carlucci et al., 2013; Szathvary and Trestini, 2013; Loke et al., 2015) to determine the effects of the features of UHT milk on price. Because the relationship between price and attributes (equation [1]) was left unspecified by theory, it was necessary to choose the functional form that fit the data best (Costanigro and McCluskey, 2011). Among the functional forms suggested, the literature proposes linear, semi-logarithmic, inverse, and Box-Cox transformations. The selection of the best functional form can be performed using a BoxCox test; however, in our case, the Box-Cox test showed that no functional form was clearly preferred over the others. Following Carlucci et al. (2013) and Loke et al. (2015), we used a semi-logarithmic specification of the hedonic price equation:

$$
\begin{aligned}
\ln P_{j}= & a_{0}+\sum_{h=1}^{H} \beta_{f h} \mathbf{Z}_{h}^{\mathrm{HI}}+\sum_{c=1}^{C} \beta_{c} \mathbf{Z}_{c}^{\mathbf{C C}}+\sum_{o=1}^{O} \beta_{o} \mathbf{Z}_{o}^{\mathbf{O C}}+\sum_{p=1}^{P} \beta_{p} \mathbf{Z}_{p}^{\mathbf{P}} \\
& +\sum_{i=1}^{I} \beta_{i} \mathbf{Z}_{i}^{\mathbf{I}}+\sum_{r=1}^{R} \beta_{r} \mathbf{Z}_{r}^{\mathbf{R}}+\sum_{b=1}^{B} \beta_{b} \mathbf{Z}_{b}^{\mathbf{B}}+\sum_{t=1}^{25} \theta_{t} d_{t}+\varepsilon_{j},
\end{aligned}
$$

where we also controlled for a vector of time $\mathbf{T}$ (month) indicators, $d_{t}$, to capture average monthly variation in UHT milk prices in the data. The $\beta_{s}$ are parameters to be estimated, capturing the implicit values associated with the different UHT milk attributes, whereas the $\theta_{s}$ 
BIMBO ET AL.

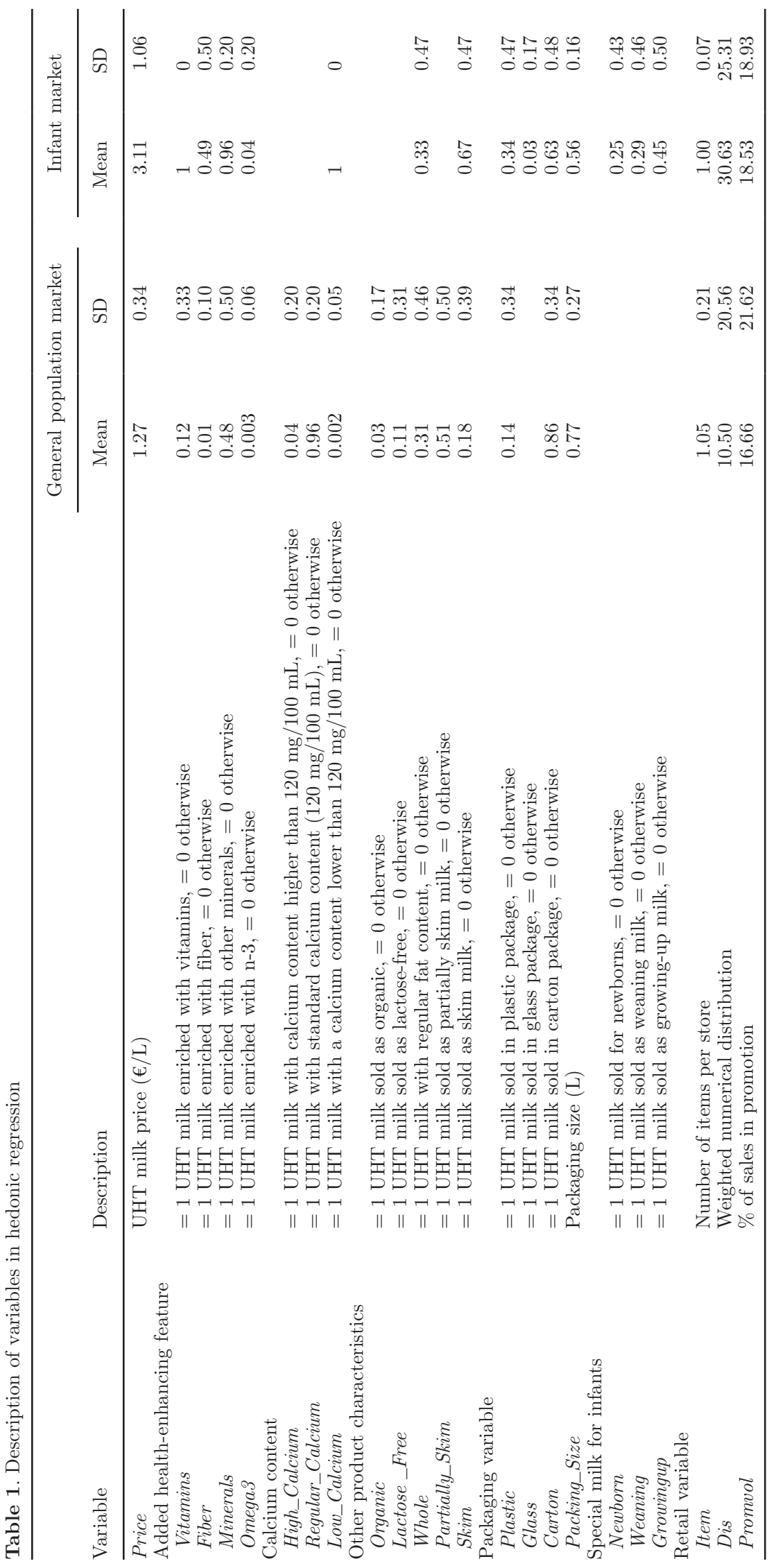


capture the effect of time on UHT milk price, and $\varepsilon_{j}$ is an idiosyncratic error term.

As the products sold more often will influence the estimates more than those sold less frequently, we corrected for magnitude bias by using the weighted least squares (WLS) estimation instead of the ordinary least squares (OLS), as suggested by Diewert (2003). Similar to Loke et al. (2015), who adopted the square root of frequency sales as the weight to correct the estimates, we used the square root of volume sales as the weight.

The marginal prices of each attribute (in percentage terms) were calculated using Kennedy's (1981) adjustment for the indicator variables and in elasticity terms (at the sample averages) for the continuous ones. Additionally, we calculated the average effect of each UHT milk attribute on price, expressed as $€$ per liter.

\section{RESULTS AND DISCUSSION}

Table 2 reports the estimated parameters of equation [2], obtained via OLS and WLS, for the UHT milk for the general population segment, whereas the estimates for the special UHT milk for infants are reported in Table 3. Our models fit the data well, as shown by the high values of adjusted $R^{2}$, ranging between 0.88 and 0.93. Further, most of the estimated coefficients were statistically significant at the $1 \%$ level. Although the OLS estimates were comparable, in magnitude and sign, to those obtained via WLS, we will proceed with the discussion of the WLS results (right panels in Tables 2 and 3), which are more reliable because they are corrected for magnitude bias in data representation. We will discuss first the results of UHT milk for the general population segment and then those of the infant segment.

The baseline UHT milk in the general population market segment was whole milk with no health-related ingredients, not sold as lactose-free, with $120 \mathrm{mg}$ of calcium per $100 \mathrm{~mL}$, and sold in carton boxes at an average price of $1.27 € / L$.

Our findings indicated that most health-related attributes added to UHT milk for general consumption had a positive and statistically significant effect on the product's price. Among them, n-3 fatty acids were the most valuable, with a premium attached to the Omegas variable of $+112.12 \%$, or $+1.435 € / L$, with everything else constant. Further, products with added fiber and vitamins showed positive premiums in measures of +14.3 and $+3.45 \%$, respectively. In terms of monetary value, adding fiber to UHT milk added a premium of $0.183 € / \mathrm{L}$, whereas a premium of $0.044 € / \mathrm{L}$ could be achieved if the product had added vitamins. On the other hand, adding minerals to UHT milk for the general market led to a price discount of $-6.91 \%$, or $-0.088 € / \mathrm{L}$, compared with the baseline option.

Table 2. Estimated parameters and percentage of premium price for UHT milk for general population market segment $(7,373 \text { observations })^{1}$

\begin{tabular}{|c|c|c|c|c|c|c|c|c|}
\hline \multirow[b]{2}{*}{ Variable } & \multicolumn{4}{|c|}{ Ordinary least squares } & \multicolumn{4}{|c|}{ Weighted least squares } \\
\hline & $\beta$ & $\mathrm{SE}$ & $\begin{array}{c}\text { Relative } \\
\text { effects (\%) }\end{array}$ & $\begin{array}{l}\text { Average effect } \\
\text { on price }\end{array}$ & $\beta$ & $\mathrm{SE}$ & $\begin{array}{c}\text { Relative } \\
\text { effects (\%) }\end{array}$ & $\begin{array}{c}\text { Average effect } \\
\text { on price }\end{array}$ \\
\hline Vitamins & 0.008 & 0.016 & 0.75 & 0.010 & $0.034^{* * *}$ & 0.013 & 3.45 & 0.044 \\
\hline Fiber & $0.157^{* * *}$ & 0.016 & 16.97 & 0.217 & $0.134^{* * *}$ & 0.022 & 14.30 & 0.183 \\
\hline Minerals & $-0.066^{* *}$ & 0.025 & -6.42 & -0.082 & $-0.072^{* * *}$ & 0.009 & -6.91 & -0.088 \\
\hline Omega3 & $0.769^{* * *}$ & 0.035 & 115.67 & 1.481 & $0.752^{* * *}$ & 0.016 & 112.12 & 1.435 \\
\hline Low_Calcium & $-0.388^{* * *}$ & 0.035 & -32.19 & -0.412 & $-0.392^{* * *}$ & 0.016 & -32.43 & -0.415 \\
\hline High_Calcium & $0.216^{* * *}$ & 0.030 & 24.07 & 0.308 & $0.191^{* * *}$ & 0.017 & 21.05 & 0.269 \\
\hline Organic & $0.551^{* * *}$ & 0.013 & 73.44 & 0.940 & $0.551^{* * *}$ & 0.008 & 73.49 & 0.941 \\
\hline Lactose_Free & $0.173^{* * *}$ & 0.039 & 18.77 & 0.240 & $0.175^{* * *}$ & 0.009 & 19.07 & 0.244 \\
\hline Skim & $-0.129^{* * *}$ & 0.022 & -12.11 & -0.155 & $-0.129 * * *$ & 0.004 & -12.14 & -0.155 \\
\hline Partially_Skim & $-0.106^{* * *}$ & 0.010 & -10.06 & -0.129 & $-0.108^{* * *}$ & 0.003 & -10.25 & -0.131 \\
\hline Plastic & $0.147^{* * *}$ & 0.026 & 15.80 & 0.202 & $0.165^{* * *}$ & 0.004 & 17.91 & 0.229 \\
\hline Packing_Size & $-0.535^{* * *}$ & 0.033 & -53.53 & -0.685 & $-0.537^{* * *}$ & 0.006 & -53.65 & -0.687 \\
\hline Item & 0.035 & 0.033 & 3.67 & 0.047 & $0.020^{* * *}$ & 0.006 & 2.10 & 0.027 \\
\hline Dis & $-0.002^{* * *}$ & 0.000 & -2.10 & -0.027 & $-0.002^{* * *}$ & 0.000 & -2.10 & -0.027 \\
\hline Promvol & $-0.003^{* * *}$ & 0.000 & -4.99 & -0.063 & $-0.003^{* * *}$ & 0.000 & -4.99 & -0.063 \\
\hline Constant & $0.506^{* * *}$ & 0.039 & & & $0.502^{* * *}$ & 0.010 & & \\
\hline Adjusted $\mathrm{R}^{2}$ & 0.8862 & & & & 0.9188 & & & \\
\hline
\end{tabular}

${ }^{1}$ Dependent variables are log-transformations of price.

${ }^{2}$ Adjustment made according to Kennedy (1981).

${ }^{3}$ For continuous variables, we presented the average elasticity values. The estimated coefficients for regional fixed effects, brand, and monthly indicators have been omitted for brevity.

** and $*^{* *}$ are 5 and $1 \%$ significance levels, respectively. Standard errors were estimated as robust standard errors. 
Table 3. Estimated parameters and percentage of premium price for UHT milk for infant population market segment $(587 \text { observations })^{1}$

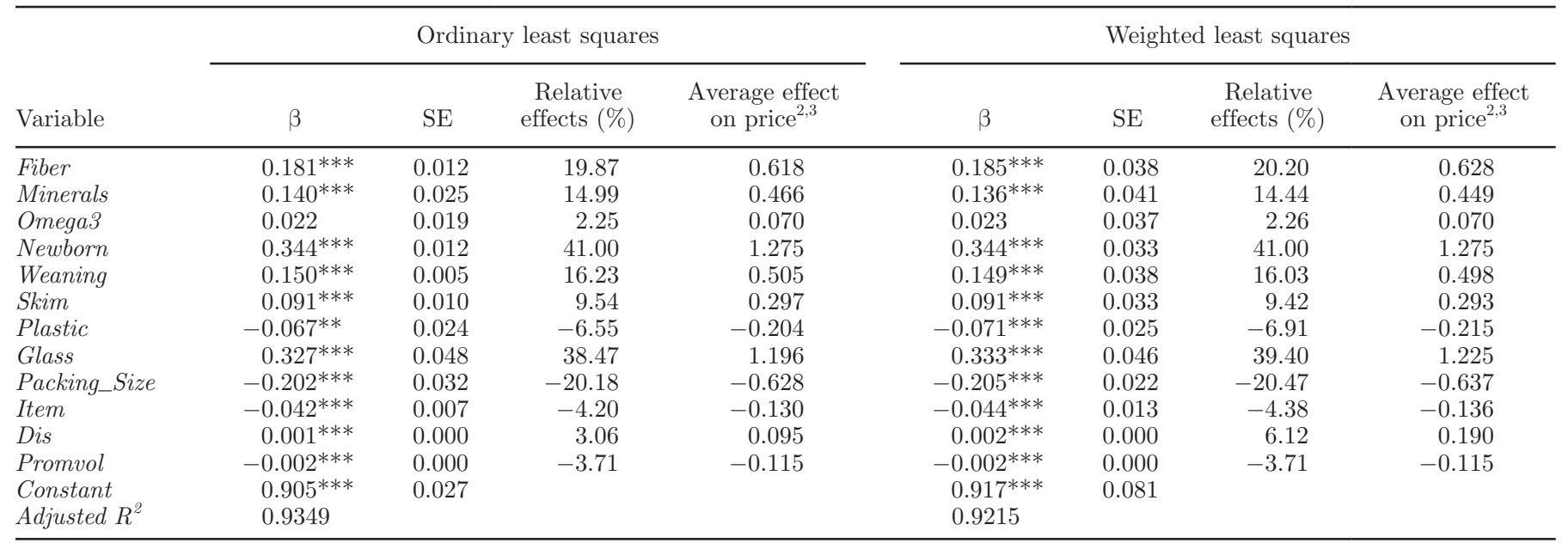

${ }^{1}$ Dependent variables are log-transformations of price.

${ }^{2}$ Adjustment made according to Kennedy (1981).

${ }^{3}$ For continuous variables, we have presented average elasticity values. The estimated coefficients for regional fixed effects, brand, and monthly indicators have been omitted for brevity.

** and ${ }^{* * *}$ are 5 and $1 \%$ significance levels, respectively. Standard errors were estimated as robust standard errors.

The estimates also showed that calcium content could be used to differentiate UHT milk in the general population market. The premium price was $+26.9 \%$ for products with calcium content above $120 \mathrm{mg} / 100$ $\mathrm{mL}$, whereas a discount was apparent $(-41.5 \%)$ for products with calcium content below that threshold. These results may be due to the high consumer acceptance of milk products with added calcium, as well as to the widespread knowledge of the role calcium plays in preventing diseases such as osteoporosis (Ares and Gámbaro, 2007).

Organic and Lactose_Free showed ceteris paribus positive and significant effects on UHT milk price in the general population segment of $+73.5 \%$ for Organic and $+19.0 \%$ for Lactose_Free (compared with the baseline option). The high market value for the organic attribute, $+0.94 € / L$, may be the result of consumers' high interest in characteristics having a halo effect (Schuldt, 2013). Products labeled as organic are, in fact, often perceived as healthier than conventional ones due to consumers believing that organic products may support human health (Hughner et al., 2007). Instead, the high premium attached to Lactose_Free may be due to the growing number of lactose-intolerant individuals who are willing to pay a premium for lactose-free dairy options, instead of having to consume nondairy alternatives such as soy milk (Mills, 2012).

Fat content affected UHT milk price among products in the general population segment. The marginal prices associated with the Skim and Partially_Skim attributes were -12.14 and $-10.25 \%$, respectively, in line with
Loke et al. (2015), who found a negative and significant relationship between the Fatfree attribute and milk prices in Hawaii. Also, the estimated coefficient for Packing_Size was negative and statistically significant $(-53.65 \%)$, consistent with previous research on other dairy products, which found a price discount associated with larger package size (e.g., Carlucci et al., 2013). Plastic packaging increased the value of UHT milk for the general public segment, as it generated a premium of $+17.91 \%$. Lastly, retail variables seemed to play a minor role in affecting UHT milk prices in this market segment, as their elasticity values ranged from -4.99 to $+2.10 \%$, but these values were, on average, smaller in magnitude than those related to product or package variables.

For the estimates for the infant segment, the baseline product in this market was whole milk for toddlers, with added vitamins, with a calcium content lower than 120 $\mathrm{mg} / 100 \mathrm{~mL}$, and sold in carton packages at an average price of $3.11 € / \mathrm{L}$. Among the attributes added to UHT milk for infants, fiber showed the highest premium at $+20.20 \%$, or $0.628 € / \mathrm{L}$, above the price of the baseline product. The premium associated with the presence of minerals was $+14.44 \%$, which corresponded to +0.45 $€ / L$. We found no statistical evidence of a premium associated with n-3 fatty acids in this segment because the Omega3 coefficient was not statistically different than zero.

Furthermore, in the special milk for the infant segment, we found that milk for newborns showed a ceteris paribus premium of $+41 \%$, or $+1.275 € / \mathrm{L}$, whereas the 
premium for weaning milk was $+16.03 \%$, or +0.498 $€ / L$, above growing-up UHT milk. Fat content also affected the price of UHT milk for infants, as the coefficient for Skim was positive and statistically significant $(+9.42 \%)$. Thus, in contrast to the general market, lowering the fat content in UHT milk for infants led to a premium price of $+0.293 € / L$ compared with the baseline product. Larger packaging size resulted in a discount in this market segment, estimated at -0.637 $€ / L$, in line with the estimates obtained for the general population segment. Plastic packaging led to a price discount of $-6.91 \%$, whereas using glass led to a (ceteris paribus) premium of $+39.4 \%$, or $1.22 € / \mathrm{L}$, compared with the baseline product. This result may be due to consumers using glass packaging to infer the wholesomeness of dairy products, as suggested by Grunert (2005), or alternatively, it may reflect the higher cost of glass compared with plastic and carton, as suggested by Silayoi and Speece (2004).

Last, the estimated elasticity values for the retail variables ranged from -4.38 to $+6.12 \%$ and point to those variables having a larger effect on infants milk's price compared with what they had on milk's price for the general population; however, their effect on price was still limited if compared with most of the coefficients related to product or package variables.

\section{CONCLUSIONS}

Our findings suggest that manufacturers of UHT milk for the general population segment may differentiate their products on the basis of health-enhancing features, as their presence was associated with a premium price. Ultra-high-temperature-treated milk seems a suitable carrier to host n-3 fatty acids, fiber, and vitamins; among these attributes, the most valuable is $\mathrm{n}-3$, showing the highest contribution to price, equal to $+1.43 € / \mathrm{L}$. Interestingly, adding minerals to UHT milk led to a price discount of $-6.91 \%$, or $-0.088 € / \mathrm{L}$. Further, UHT milk manufacturers may benefit from producing organic or lactose-free milk, as the presence of these attributes led to, respectively, the second- and third-highest premiums in the UHT milk segment for the general population. Manufacturers operating in the UHT milk segment for infants may instead find it profitable to differentiate their products on the basis of fiber and mineral content, because the presence of these attributes resulted in ceteris paribus premiums of +20.20 and $+14.44 \%$, respectively, equal to +0.628 and $+0.449 € /$ L. Adding n-3 fatty acids may not be advisable for products in this segment because the presence of this attribute did not seem to result in a premium. Instead, products for newborn infants showed high pre- miums, as did products having glass packaging $(+1.275$ and $+1.225 € / L$, respectively).

\section{ACKNOWLEDGMENTS}

The authors are grateful to the founders of project LAIFF "Reti di laboratorio per l'innovazione nel campo degli alimenti funzionali," cod. no. 47, cofinanced by the Apulia Region "Reti di Laboratori Pubblici di Ricerca" (PO Puglia FESR 2007-2013, Asse I, Linea 1.2), Italy.

\section{REFERENCES}

Ares, G., and A. Gámbaro. 2007. Influence of gender, age and motives underlying food choice on perceived healthiness and willingness to try functional foods. Appetite 49:148-158.

Carlucci, D., A. Stasi, G. Nardone, and A. Seccia. 2013. Explaining price variability in the Italian yogurt market: A hedonic analysis. Agribusiness 29:194-206.

Chandarana, D., B. Frey, L. Stewart, and J. Mattick. 2006. UHT milk processing - Effect on process energy requirements. J. Food Sci. 49:977-978.

Chow, G. C. 1960. Tests of equality between sets of coefficients in two linear regressions. Econometrica 28:591-605.

Combris, P., S. Lecocq, and M. Visser. 1997. Estimation of a hedonic price equation for Bordeaux wine: Does quality matter? Econ. J. 107:390-402.

Costanigro, M., and J. McCluskey. 2011. Hedonic price analysis in food markets. Pages 152-180 in The Oxford Handbook of the Economics of Food Consumption and Policy. J. L. Lusk, J. Roosen, and A. Shogren, ed. Oxford University, Oxford, UK.

Diewert, E. 2003. Hedonic regressions: A review of some unresolved issues. Page 43 in Proc. 7th Meet. Ottawa Group, Paris, France.

Euromonitor. 2014. Dairy in Italy. Euromonitor International. Accessed Jun. 28, 2015. http://www.euromonitor.com/dairy-in-italy/ report.

Grunert, K. G. 2005. Innovation in Agri-Food Systems: Product Quality and Consumer Acceptance. Wageningen Academic Publishers, Wageningen, the Netherlands.

Hughner, R. S., P. McDonagh, A. Prothero, C. J. I. I. Shultz, and J. Stanton. 2007. Who are organic food consumers: A compilation and review of why people purchase organic food. J. Consum. Behav. 6:94-110.

Kennedy, P. 1981. Estimation with correctly interpreted dummy variables in semilogarithmic equation. Am. Econ. Rev. 71:801.

Ladd, G. W., and V. Suvannunt. 1976. A model of consumer goods characteristics. Am. J. Agric. Econ. 58:504-510.

Loke, M. K., X. Xu, and P. Leung. 2015. Estimating organic, local, and other price premiums in the Hawaii fluid milk market. J. Dairy Sci. 98:2824-2830

Lusk, J. L., T. Feldkamp, and T. C. Schroeder. 2014. Experimental auction procedure: Impact on valuation of quality differentiated goods. Am. J. Agric. Econ. 86:389-405.

Mills, M. 2012. Lactose-free dairy: Opportunities, strategies and key case studies. Ingredient Communications. Accessed Jun. 5, 2015. https://www.new-nutrition.com/report/showReport/883.

Muehlhoff, E., A. Bennett, and D. McMahon. 2013. Milk and dairy products in human nutrition. Food and Agriculture Organization of the United Nations (FAO).

Oupadissakoon, G., and D. Chambers. 2009. Comparison of the sensory properties of ultra-high-temperature (UHT) milk from different countries. J. Sens. Stud. 24:427-440.

Panzone, L. A. 2011. The lost scent of Eastern European wines in Western Europe: A hedonic model applied to the UK market. Br. Food J. 113:1060-1078. 
Pieri, R. 2009. Il mercato del latte. Rapporto 2009. Osservatorio del latte-SMEA, Franco Angeli, Milano, Italy.

Rosen, S. 1974. Hedonic prices and implicit markets: Product differentiation in pure competition. J. Polit. Econ. 82:4-55.

Schollenberg, L. 2012. Estimating the hedonic price for fair trade coffee in Sweden. Br. Food J. 114:428-446.

Schuldt, J. P. 2013. Does green mean healthy? Nutrition Label color affects perceptions of healthfulness. Health Commun. 28:814-821.

Silayoi, P., and M. Speece. 2004. Packaging and purchase decisions: A focus group study on the impact of involvement level and time pressure. Br. Food J. 106:607-628.

Solomon, M. R. 2009. Consumer Behavior: Buying, Having, and Being. Prentice Hall, Upper Saddle River, NJ.

Steiner, B. E. 2004. Australian wines in the British wine market: A hedonic price analysis. Agribusiness 20:287-307.

Szathvary, S., and S. Trestini. 2013. A hedonic analysis of nutrition and health claims on fruit beverage products. J. Agric. Econ. 65:505-517.
Tempesta, T., and D. Vecchiato. 2013. An analysis of the territorial factors affecting milk purchase in Italy. Food Qual. Prefer. 27:3543.

Tomasula, P. M., N. Datta, W. C. F. Yee, A. J. McAloon, D. W. Nutter, F. Sampedro, and L. M. Bonnaillie. 2014. Computer simulation of energy use, greenhouse gas emissions, and costs for alternative methods of processing fluid milk. J. Dairy Sci. 97:4594-4611.

Transparency Market Research. 2013. UHT milk market-Global industry analysis, size, share, growth, trends, and forecast 2013-2019. Accessed Jun. 6, 2015. http://www.transparencymarketresearch. com/uht-milk-market.html.

Troiani, C. 2014. Il latte-Forte competizione di prezzo nel latte UHT. Accessed Jun. 6, 2015. http://www.lattenews.it/fortecompetizione-di-prezzo-nel-latte-uht-2/.

Walstra, P., P. Walstra, J. T. Wouters, and T. J. Geurts. 2005. Dairy Science and Technology. CRC Press, Boca Raton, FL. 